\title{
Evaluation Method of Reservoir Producing Status Based on Cumulative Distribution Curve of Oil Displacement Efficiency
}

\author{
Cuo Guan, ${ }^{1,2}$ Chengfang Shi, ${ }^{2}$ Dacheng $\mathrm{Wu}^{1}{ }^{1}$ Wenrui $\mathrm{Hu},{ }^{1,3}$ and Zhaoliang $\mathrm{Li}^{2}$ \\ ${ }^{1}$ Research Institute of Enhance Oil Recovery, China University of Petroleum, Beijing 102249, China \\ ${ }^{2}$ Research Institute of Petroleum Exploration \& Development, PetroChina, Beijing 100083, China \\ ${ }^{3}$ Chinese Academy of Engineering, Beijing 100088, China \\ Correspondence should be addressed to Cuo Guan; guancuo@163.com
}

Received 15 February 2017; Accepted 28 May 2017; Published 4 July 2017

Academic Editor: Anna Pandolfi

Copyright (C) 2017 Cuo Guan et al. This is an open access article distributed under the Creative Commons Attribution License, which permits unrestricted use, distribution, and reproduction in any medium, provided the original work is properly cited.

\begin{abstract}
This paper provides a method for evaluating the status of old oilfield development. This method mainly uses the abundant coring well data of the oilfield to obtain the cumulative distribution curve of the displacement efficiency after the displacement efficiency of the statistical wells in the study area in a similar period is ordered from small to large. Based on the cumulative distribution curve of displacement efficiency, combined with the reservoir ineffective circulation limit, the cumulative water absorption ratio of reservoirs and other data are used to study the reservoir producing degree, calculate the degree of oil recovery, evaluate the proportion of the remaining movable oil after water flooding, calculate the reservoir ineffective circulation thickness and ineffective circulation water volume, and so on.
\end{abstract}

\section{Introduction}

At present, most of China's oilfields have entered the stage of high water-cut development, in which the remaining oil in the reservoir is scattered, resulting in increasing difficulty of further potential tapping $[1,2]$. Therefore, effective estimation of the reservoir producing status plays a vital role in the accurate evaluation of oilfield development effect. There are many methods for evaluating the reservoir producing status [3]. Based on the specialty, they are divided into geological and seismic methods: reservoir engineering [4], well test [5], numerical simulation methods, indoor experimental techniques, and so on. These methods have their own advantages and disadvantages. Practice shows that sealing coring well data can be used to give an intuitive, accurate, and quantitative description of the remaining oil distribution. Therefore, the rational use of existing coring well data and the statistical analysis of the oil displacement efficiency distribution can provide an effective means for thoroughly dissecting the reservoir producing status and the oil displacement status [6], which is of great significance for the quick and accurate evaluation of oilfield development status and the improvement of oil recovery.

\section{Evaluation Method Is Put Forward}

Due to various development factors and geological factors, the distribution of remaining oil in the later stage of oilfield development presents a strong heterogeneity. According to the statistical results of the oil displacement efficiency of 1953 samples from 715 formations of 24 coring wells in an oilfield in a short period of time, the cumulative distribution curve of reservoir oil displacement efficiency is Sshaped. The logarithmic function, semilogarithmic function, and hyperbolic tangent function are used to fit the curve. It is found that degree of fitting between the cumulative probability distribution curve of the displacement efficiency and the hyperbolic tangent function is better [7]. Therefore, the hyperbolic tangent function is used to fit the cumulative probability distribution curve of displacement efficiency. As shown in Figure 1, curve A shows the cumulative distribution curve of the displacement efficiency at the time of taking out 


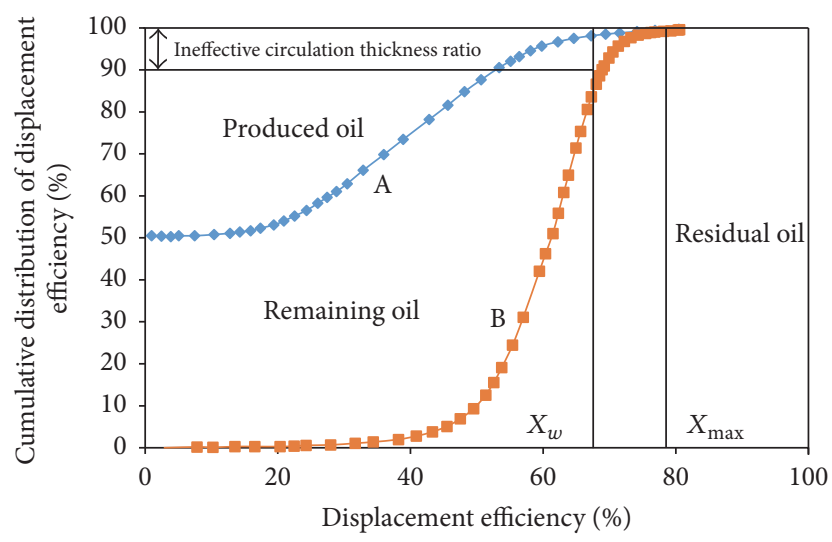

FIGURE 1: Schematic diagram of the cumulative distribution curve of displacement efficiency.

the core of the well, while curve B shows the cumulative probability distribution curve of the displacement efficiency under the residual oil saturation. The mathematical expressions of the curves A and B are, respectively,

$$
\begin{aligned}
& f(E d)=\frac{C_{1}}{1+e^{-A_{1} E d+B_{1}}}+D_{1}, \\
& g(E d)=\frac{C_{2}}{1+e^{-A_{2} E d+B_{2}}}+D_{2},
\end{aligned}
$$

where $f(E d)$ is the mathematical formula of the hyperbolic tangent function for the cumulative distribution curve of the displacement efficiency at the time of taking out the core of the well, in which the value range is $0-1 ; E d$ is the displacement efficiency at the time of taking out the core of the well, in which the value range is $0-1 ; A_{1}, B_{1}, C_{1}$, and $D_{1}$ are parameters obtained by fitting; $g(E d z)$ is the mathematical formula of the hyperbolic tangent function for the cumulative probability distribution curve of the displacement efficiency under the residual oil saturation, in which the value range is $0-1 ; E d z$ is the displacement efficiency under the residual oil saturation, in which the value range is $0-1 ; A_{2}, B_{2}, C_{2}$, and $D_{2}$ are parameters obtained by fitting.

2.1. Selection of Curve Fitting Method. The parameters in the function are obtained by the least squares curve fitting [8]. Since the observed value $y_{i}$ fluctuates around the desired value $f\left(E d_{i}, A, B, C, D\right)$, its distribution is normal distribution, and when $(A, B, C, D)$ is represented by $E$, the probability density of $y_{i}$ is

$$
p\left(y_{i}\right)=\frac{1}{\sqrt{2 \pi} \sigma_{i}} \operatorname{ex}\left\{-\frac{\left[y_{i}-f\left(d_{i}, E\right)\right]^{2}}{2 \sigma_{i}^{2}}\right\} .
$$

Considering that the measurements are independent of each other, the likelihood function of the observed values $y_{1}, y_{2}, \ldots, y_{N}$ is

$L$

$$
=\frac{1}{(\sqrt{2 \pi})^{N} \sigma_{1} \sigma_{2} \ldots \sigma_{N}} \operatorname{ex}\left\{-\frac{1}{2} \sum_{i=1}^{N} \frac{\left[y_{i}-f\left(d_{i}, E\right)\right]^{2}}{\sigma_{i}^{2}}\right\} .
$$

Assume the likelihood function $L$ be the largest to estimate the parameter $C$, which should be

$$
\sum_{i=1}^{N} \frac{\left[y_{i}-f\left(E d_{i}, E\right)\right]^{2}}{\sigma_{i}^{2}} .
$$

Take the minimum, that is, the least squares criterion. To obtain $E$, it is necessary to make

$$
\begin{aligned}
\sum_{i=1}^{N} \frac{1}{\sigma_{i}^{2}}\left[y_{i}-f\left(E d_{i}, A, B, C, D\right)\right] \frac{\partial f\left(E d_{i}, E\right)}{\partial E_{j}} & =0, \\
j & =1,2,3,4 .
\end{aligned}
$$

Solve the equation set to obtain $A, B, C, D$, and then we obtain the equation $f\left(E d_{i}, A, B, C, D\right)$ of the curve.

2.2. Verification of the Accuracy of the Fitting Method. According to the statistics, it is found that the probability distribution of displacement efficiency follows the normal distribution $N\left(\mu, \sigma^{2}\right)$, where $\mu$ is the mean of the normal distribution and $\sigma$ is the standard deviation of the normal distribution. Therefore, the cumulative probability distribution of the displacement efficiency is

$$
f(E d)=\int_{0}^{E d} \frac{1}{\sqrt{2 \pi}} e^{-(x-\mu)^{2} / 2 \sigma^{2}} d E d .
$$

Based on the simultaneous equations consisting of cumulative probability distribution function of the displacement efficiency and the cumulative probability distribution function obtained by fitting, $E d_{1}$ and $E d_{2}$ are substituted into the equation to obtain the equations of $\mu$ and $\sigma$ :

$$
\begin{aligned}
& \int_{0}^{E d_{1}} \frac{1}{\sqrt{2 \pi}} e^{-(x-\mu)^{2} / 2 \sigma^{2}} d E d=\frac{C}{1+e^{-A E d_{1}+B}}+D, \\
& \int_{0}^{E d_{2}} \frac{1}{\sqrt{2 \pi} \sigma} e^{-(x-\mu)^{2} / 2 \sigma^{2}} d E=\frac{C}{1+e^{-A E d_{2}+B}}+D .
\end{aligned}
$$

$\mu$ and $\sigma$ obtained by the method used in this paper can be obtained through inverse computation according to (7), which are compared with the $\mu$ and $\sigma$ in the actual data to determine the accuracy of the selected fitting method.

\section{Evaluation Index Calculation}

Based on the cumulative probability distribution curve of displacement efficiency, the development indexes such as the reservoir producing degree, the degree of recovery, the proportion of the remaining movable oil after water flooding, the ineffective circulation thickness, and the ineffective circulation water volume are evaluated. The calculation method is as follows.

3.1. Producing Degree. When the oil displacement efficiency $E d=0$, the ratio of nonproducing reserves of the reservoir $h_{\mu}$ is

$$
\left.h_{\mu}\right|_{E d=0}=f(0)=\frac{C_{1}}{1+e^{B_{1}}}+D_{1} .
$$


Producing degree of reservoir $M$,

$$
M=1-\frac{C_{1}}{1+e^{B_{1}}}-D_{1}
$$

where $h_{\mu}$ is the proportion of nonproducing reserves of the reservoir and $M$ is the producing degree of reservoir.

3.2. Degree of Recovery. Proportion of crude oil in the reservoir is as follows:

$$
\begin{aligned}
N_{R}= & \int_{0}^{E d_{\max }} f(E d) d E d+\left(1-E d_{\max }\right) \\
= & \int_{0}^{E d_{\max }}\left(\frac{C_{1}}{1+e^{-A_{1} E d+B_{1}}}+D_{1}\right) d E d \\
& +\left(1-E d_{\max }\right) \\
= & \frac{C_{1}}{A_{1}} \ln \frac{e^{A_{1} E d_{\max }+e^{B_{1}}}}{1+e^{B_{1}}}+\left[1-\left(1-D_{1}\right) E d_{\max }\right] .
\end{aligned}
$$

Degree of reservoir recovery $R$ is as follows:

$$
R=1-N_{R}=\left(1-D_{1}\right) E d_{\max }-\frac{C_{1}}{A_{1}} \ln \frac{e^{A_{1} E d_{\max }+e^{B_{1}}}}{1+e^{B_{1}}},
$$

where $N_{R}$ is the proportion of crude oil in the reservoir, $R$ is the degree of reservoir recovery, and $E d_{\text {max }}$ is the maximum displacement efficiency corresponding to the cumulative distribution curve of the displacement efficiency at the time of taking out the core of the well.

3.3. Proportion of Remaining Movable Oil. The proportion of residual oil in the reservoir $N_{O R}$ is

$$
\begin{aligned}
N_{O R}= & \int_{E d z_{\min }}^{E d z_{\max }}\left(\frac{C_{2}}{1+e^{-A_{2} E d+B_{2}}}+D_{2}\right) d E d \\
& +\left(1-E d_{\max }\right) \\
= & \frac{C_{2}}{A_{2}} \ln \frac{e^{A_{2} E d z_{\max }-B_{2}}+1}{e^{A_{2} E d z_{\min }-B_{2}}+1}+D_{2} \\
& *\left(E d z_{\max }-E d z_{\min }\right)+\left(1-E d_{\max }\right) .
\end{aligned}
$$

The proportion of remaining movable oil $N_{R P}$ is

$$
\begin{aligned}
N_{R P}= & E d z_{\max }-E d_{\max } \\
& +\int_{0}^{E d_{\max }}\left(\frac{C_{1}}{1+e^{-A_{1} E d+B_{1}}}+D_{1}\right) d E d \\
& -\int_{C_{\max }}^{E d z_{\min }}\left(\frac{C_{2}}{1+e^{-A_{2} E d+B_{2}}}+D_{2}\right) d E d \\
= & \left(1-D_{2}\right) E d z_{\max }-\left(1-D_{1}\right) E d_{\max } \\
& +D_{2} E d z_{\min }+\frac{C_{1}}{A_{1}} \ln \frac{e^{A_{1} E d_{\text {max }}+e^{B_{1}}}}{1+e^{B_{1}}} \\
& -\frac{C_{2}}{A_{2}} \ln \frac{e^{A_{2} E d z_{\text {max }}-B_{2}}+1}{e^{A_{2} E d z_{\text {min }}-B_{2}}+1},
\end{aligned}
$$

where $E d z_{\text {max }}$ is the maximum displacement efficiency corresponding to the cumulative probability distribution curve of the displacement efficiency under residual oil saturation; $E d z_{\text {min }}$ is the minimum displacement efficiency corresponding to the cumulative probability distribution curve of the displacement efficiency under residual oil saturation; $N_{O R}$ is the proportion of residual oil in the reservoir; $N_{R P}$ is the proportion of the remaining movable oil; $N_{R}$ is the proportion of crude oil in the reservoir.

3.4. Ineffective Circulation Thickness. The water cut and flooding efficiency data of the reservoir are obtained by using the single-layer oil test data of the reservoir and then statistical regression of the water cut and displacement efficiency is carried out to obtain the relation curve between the water cut and the water saturation. The displacement efficiency corresponds to the relation curve between the water saturation. With the water cut of $98 \%$ as the limit, the critical water saturation of the ineffective circulation layer is determined by the relation curve between water cut and water saturation; then the relation curve between the displacement efficiency and the water saturation is used to find the oil displacement efficiency corresponding to the oil saturation and determine the critical oil displacement efficiency limit $E d_{w}$. With the critical oil displacement efficiency of ineffective circulation as the limit, the reservoir thickness exceeding the displacement efficiency value enters the ineffective circulation state.

3.5. Ineffective Circulation Water Volume. The proportion of the water absorption per unit of thickness in the total water injection of the well in the study area is ranked from small to large. The percentage of the thickness of different water absorption ratios in the total thickness is calculated, which is called the thickness frequency in the thickness of water absorption ratio, and then the cumulative water absorption ratio distribution map corresponding to the reservoir thickness is obtained. According to the current ineffective circulation thickness ratio $h_{w 1}$, which has been determined, the corresponding water absorption ratio (i.e., the current ineffective circulation water volume $q_{w}$ ) can be calculated.

\section{Example Calculation}

Taking the coring well data of a block in Lasaxing Oilfield of Daqing as an example, the cumulative probability distribution curve of the displacement efficiency at the time of taking out the core of the well and the cumulative probability distribution curve of the displacement efficiency under the residual oil saturation are obtained (Figure 2).

The cumulative distribution curve of the displacement efficiency at the time of taking out the core of the well and the cumulative probability distribution curve of the displacement efficiency under the residual oil saturation are fitted by using the method of this paper to obtain the hyperbolic tangent function for the cumulative distribution curve of the displacement efficiency at the time of taking out the core of 


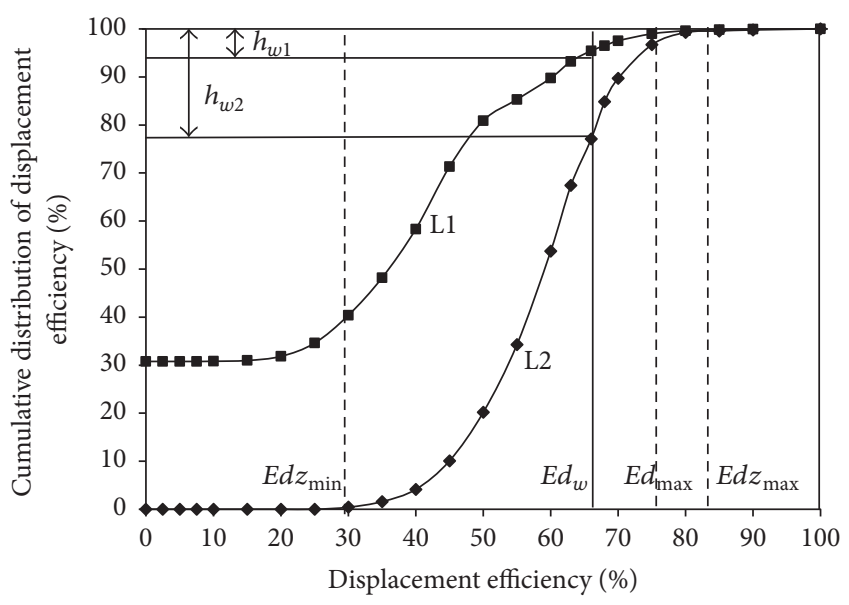

FIGURE 2: Cumulative distribution curve of displacement efficiency.

the well and the cumulative probability distribution curve of the displacement efficiency under the residual oil saturation:

$$
f(E d)=\frac{0.7001}{1+e^{-12.62 * E d+5.413}}+0.2951
$$

Calculated values are as follows:

Mean: $\mu=0.6138$; standard deviation $\sigma=0.1256$.

Measured values are as follows:

Mean: $\mu=0.6$; standard deviation $\sigma=0.175$.

Mean error: $2.3 \%$; standard deviation error: $2.8 \%$

$$
g(E d)=\frac{1.013}{1+e^{-16.96 * E d+9.981}}+0.000612 .
$$

The parameters obtained by the method used in this paper are as follows: the reservoir producing degree is $71.59 \%$, the degree of recovery is $35.13 \%$, and the proportion of the remaining movable oil after water flooding is $22.82 \%$, respectively. Based on the relation curve between the water cut and the water saturation (Figure 3 ) and the relation curve between water saturation and oil displacement efficiency (Figure 4), the current ineffective circulation thickness ratio $h_{w 1}$ and the final ineffective circulation thickness ratio can be determined, which is $5 \%$ and $21 \%$, respectively. Based on the cumulative water absorption ratio distribution map (Figure 5), we can see that the proportion of the current ineffective circulation water volume is about $12 \%$, which is basically the same as value obtained from the numerical simulation method. Therefore, the method has good applicability and practicability.

\section{Conclusion}

After the analysis of the actual core data, the cumulative probability distribution curve of the displacement efficiency is obtained, and the hyperbolic tangent formula for the cumulative distribution curve of the oil displacement efficiency is fitted by the least squares curve fitting method. Based on the cumulative distribution curve of oil displacement efficiency,

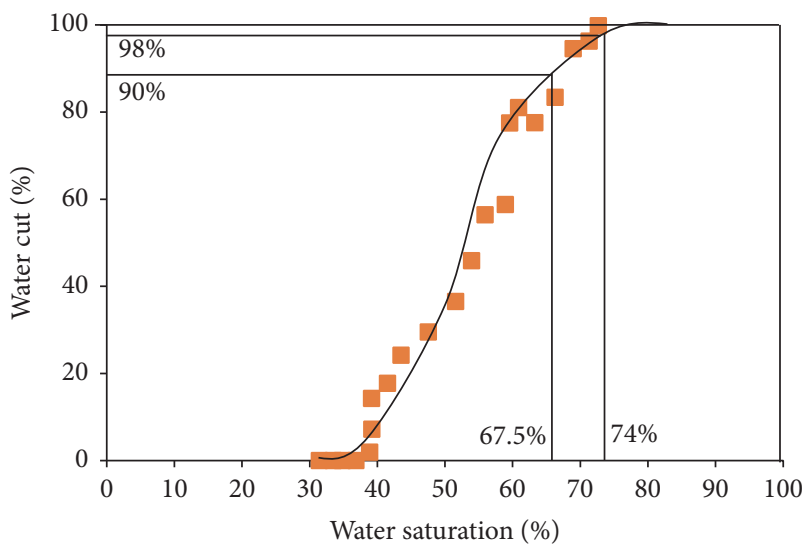

FIGURE 3: Statistical relation curve between water cut and water saturation.

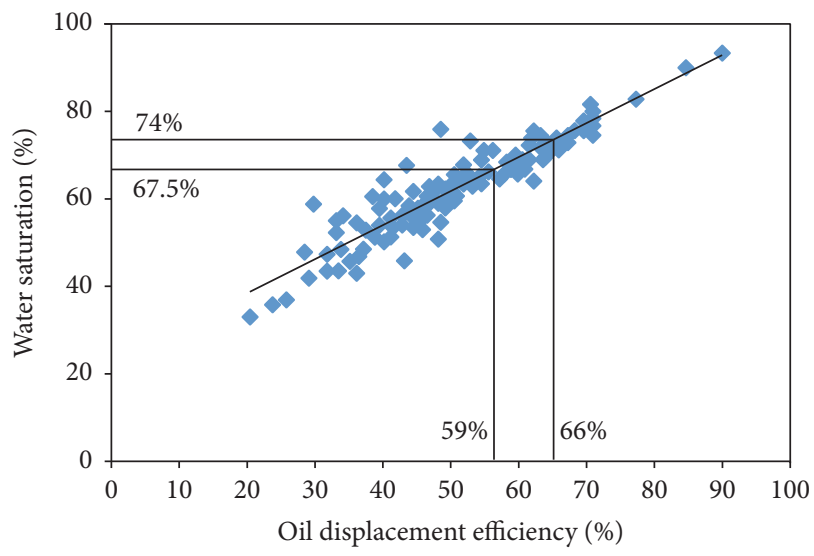

FIGURE 4: Relation curve between water saturation and oil displacement efficiency.

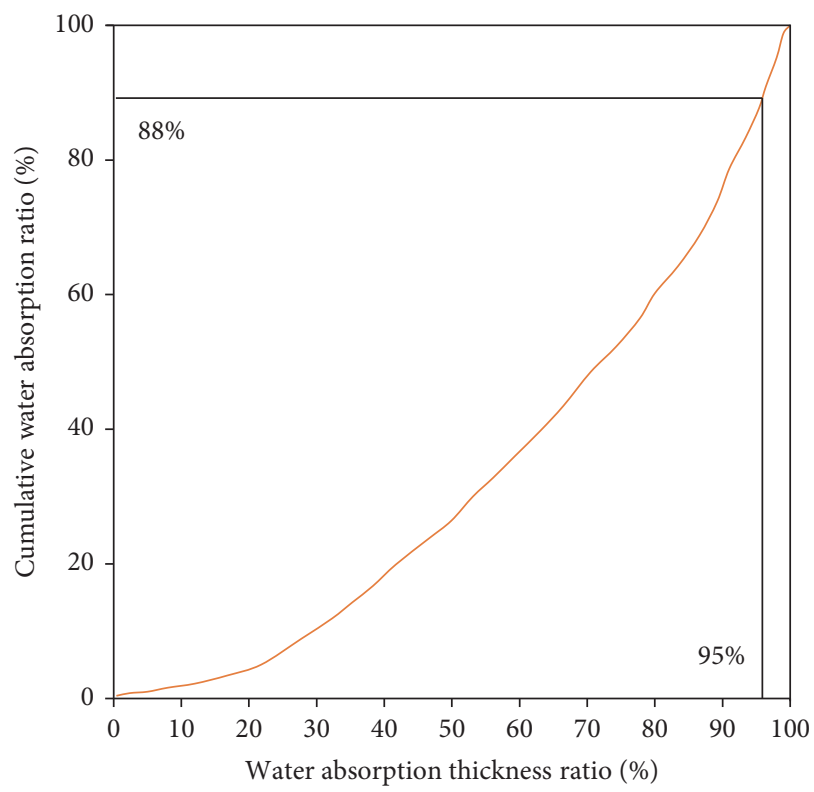

FIgURE 5: Cumulative water absorption ratio distribution map. 
the reservoir development indexes such as the reservoir producing degree, the degree of recovery, the potential of the remaining movable oil, the ineffective circulation thickness, and the ineffective circulation water volume are calculated. Through the application of this method in the actual block, we can see that the method has good accuracy and practicability. In summary, with full use of existing coring well data and the statistical analysis of the oil displacement efficiency distribution, the evaluation method can be used as a powerful tool for deep dissection of the reservoir producing status and the oil displacement status, which is of great significance for the quick and accurate evaluation of oilfield development status and the improvement of oil recovery.

\section{Conflicts of Interest}

The authors declare that there are no conflicts of interest regarding the publication of this paper.

\section{Acknowledgments}

The authors would like to acknowledge the National Major Projects of China (Grant no. 2016ZX05010-003) for the financial support during this research.

\section{References}

[1] Q. Du, L. Qing, B. Cheng, and Q. Wang, "Research on the method of determination for remaining oil at late period of high water cut stage," in Proceedings of the SPE International Oil and Gas Conference and Exhibition in China, Beijing, China, 1998.

[2] L. Zhu, Q. Du, X. Jiang et al., "Characteristics and strategies of three major contradictions for continental facies multi-layered sandstone reservoir at ultra-high water cut stage," Acta Petrolei Sinica, vol. 36, no. 2, pp. 210-216, 2015.

[3] B. D. Poe, W. K. Atwood, J. J. Kohring, and K. Brook, "Evaluation of commingled reservoir properties using production logs," in Proceedings of the International Oil Conference and Exhibition in Mexico, Society of Petroleum Engineers, Cancun, Mexico, 2006.

[4] J. Mohammad and A. Siavash, "Reservoir evaluation in undersaturated oil reservoirs using modern production data analysis: a simulation study," Science International, vol. 26, pp. 1089-1094, 2014.

[5] L. Tian, Y. Shen, S. He, F. Ma, G. Luan, and X. Guo, "Research and application of deconvolution in well test analysis of extralow permeability sandstone reservoirs," Petroleum Science and Technology, vol. 30, no. 22, pp. 2348-2359, 2012.

[6] A. M. Al-Dhafeeri and H. A. Nasr-El-Din, "Evaluation of commingled reservoir properties using production logs," Journal of Petroleum Science and Engineering, vol. 55, pp. 18-36, 2007.

[7] W. F. Maddams, "The Scope and Limitations of Curve Fitting," Applied Spectroscopy, vol. 34, no. 3, pp. 245-267, 1980.

[8] X. Liu and Y. F. Wang, "Research of automatically piecewise polynomial curve-fitting method based on least-square principle," Science Technology and Engineering, vol. 14, no. 3, pp. 55-58, 2014. 


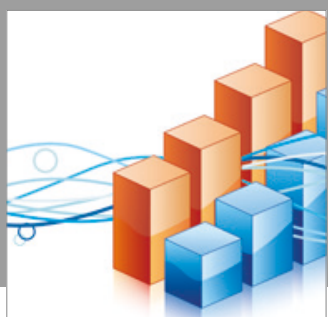

Advances in

Operations Research

vatersals

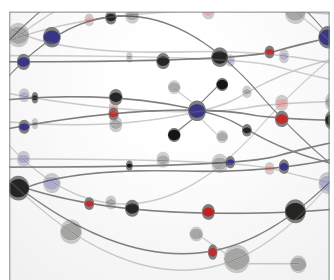

\section{The Scientific} World Journal
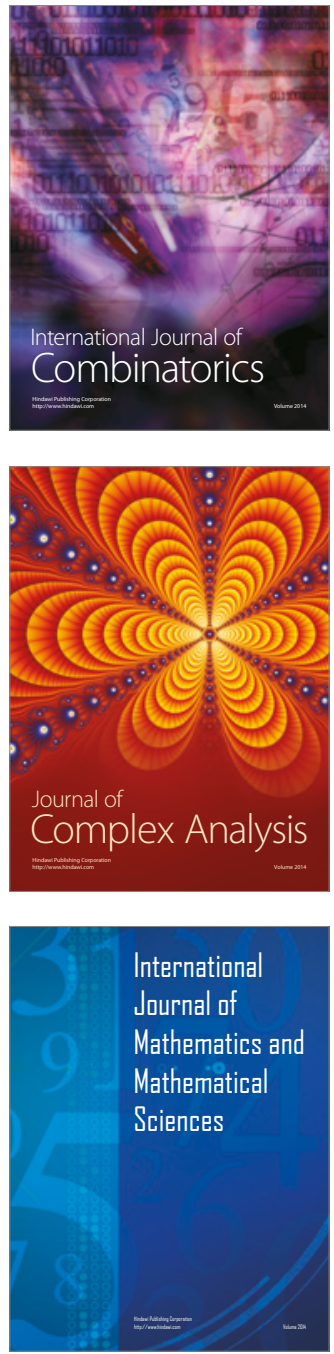
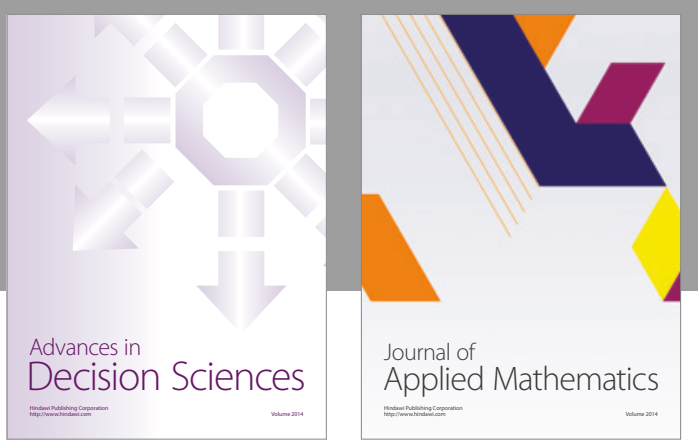

Algebra

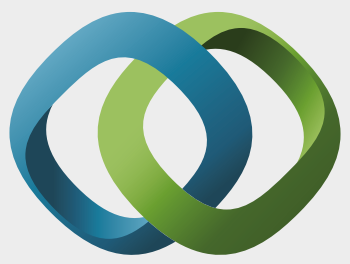

\section{Hindawi}

Submit your manuscripts at

https://www.hindawi.com
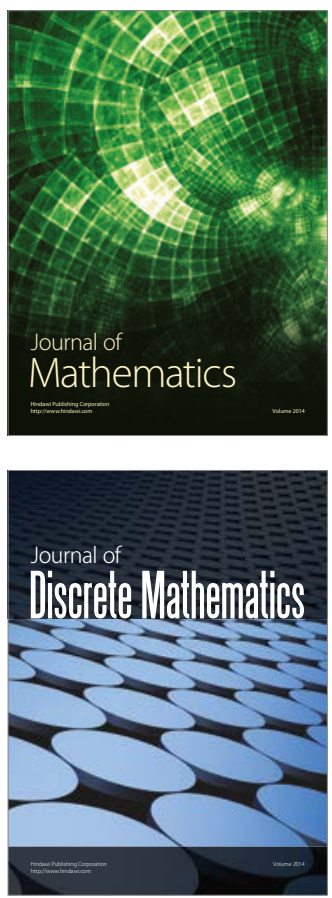

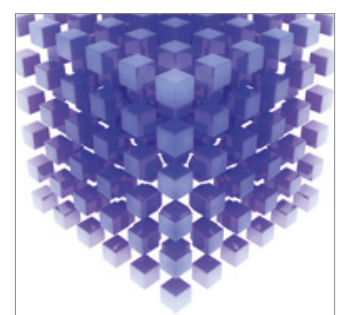

Mathematical Problems in Engineering
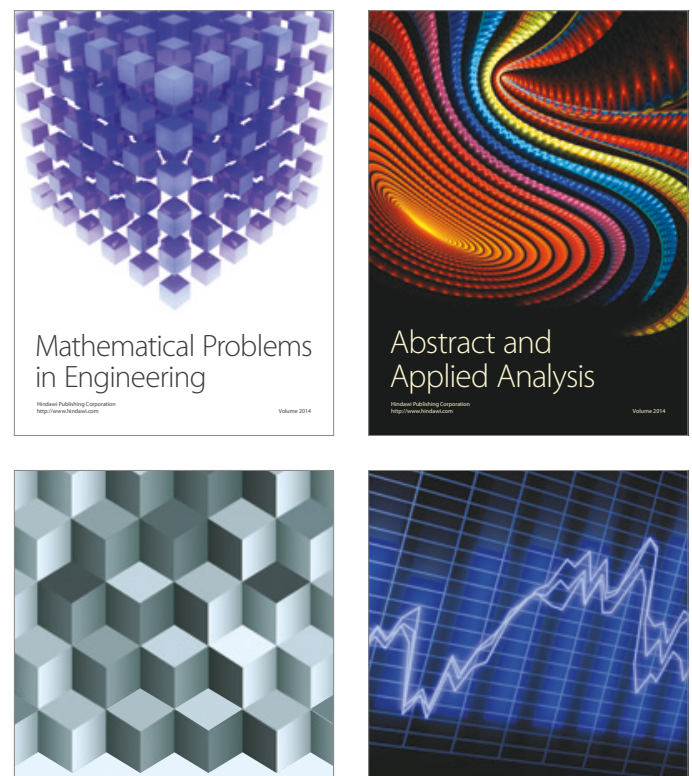

Journal of

Function Spaces

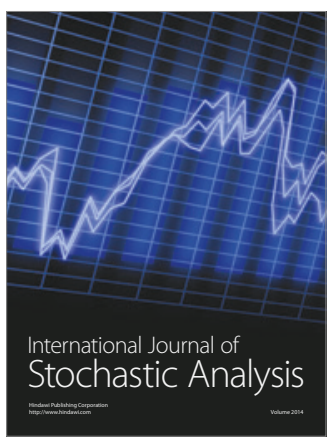

Probability and Statistics
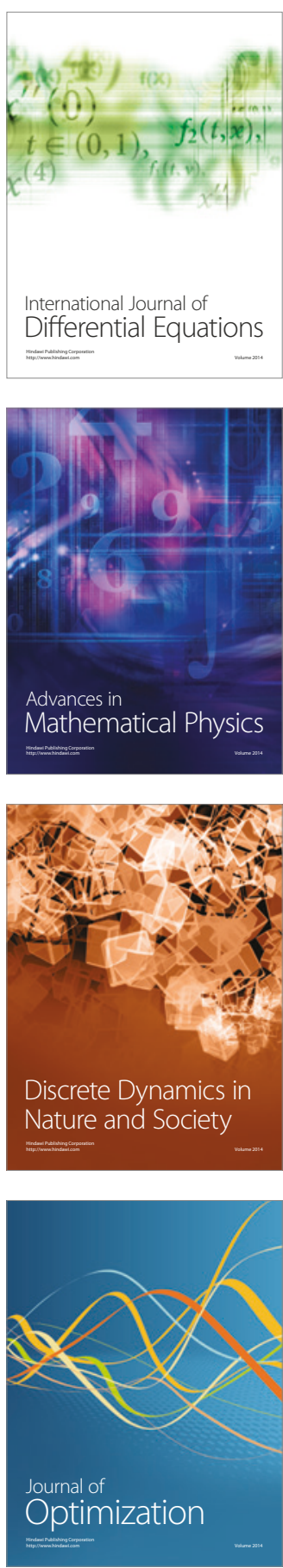